DOI: $10.25178 /$ nit.2017.2.11

\section{РАЗВИТИЕ СОВРЕМЕННОЙ МУЗЫКАЛЬНОЙ
КУЛЬТУРЫ ТУВЫ
(ВЗГЛЯД ИЗ ЯПОНИИ) МУЗЫКАЛЬНОЙ
КУЛЬТУРЫ ТУВЫ
(ВЗГЛЯД ИЗ ЯПОНИИ) МУЗЫКАЛЬНОЙ
КУЛЬТУРЫ ТУВЫ
(ВЗГЛЯД ИЗ ЯПОНИИ)}

Мао Терада

Независимый автор, Япония

\author{
THE DEVELOPMENT \\ OF CONTEMPORARY \\ MUSIC CULTURE \\ OF TUVA \\ (A VIEW FROM JAPAN)
}

\author{
Mao Terada \\ Independent author, \\ Japan
}

Выпускница-филолог Университета Вако из 2.Токио впервые услышала тувинскую музыку в 1999 г. на компакт диске всемирно известной группы «Хун-Хурту». Начала учиться исполнять хоомей. В 2000-х годах приезжала в Туву для участия в музыкальных фестивалях, а с 2006 г. осталась здесь для изучения музыкальных традиций. Автор наблюдает, что музыкальная жизнь Тувы не стоит на месте, а постоянно развивается. В статье делится результатами своих личных наблюдений и своими интересными соображениями о том, как и в какую сторону развивается тувинская музыка на современном этапе.

Автор называет причины большого интереса японцев к тувинскому горловому пению. Жители урбанизированной страны испытывают дефицит «живых» впечатлений, оторваны от природы. В Японии почти не осталось сказителей и исполнителей на древних музыкальных инструментах, очень редким явлением стало чтение буддийскими ламами сутр. Грусть японцев по старинным звукам компенсируется звуками хоомея и тувинских песен, выражающих разные настроения, имеющих большое количество жанров. Удивительно многообразие тувинских музыкальных инструментов. Количество исполнителей хоомея в Японии постоянно растет. Японские исполнители хоомея каждый год приглашают тувинских хоомейжи к себе и

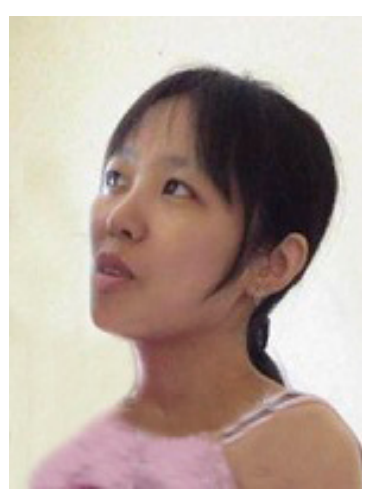

A philologist, graduate of Wako University (Tokyo), first heard Tuvan music in 1999 from a CD of a world-renowned band "Huun Huur Tu". She started learning to perform xöömei. In 2000s she visited Tuva to participate in musical festivals, and in 2006 she decided to stay here to study music traditions. The musical life of Tuva does not stand still and steadily develops. In this article the author shares her personal observations and opinions on whether how and which direction does the contemporary Tuvan music evolve.

There are a number of reasons for profound interest of the Japanese in Tuvan throat singing. Citizens of urbanized country, they feel the lack of "live" impressions, they are detached from the environment. Japan has almost no tale-tellers or ancient music instrument players left, reading sutras by Buddhist lamas became a very rare thing. Japanese compensate their sorrow for ancient sounds with the sounds of xöomei and Tuvan songs that express different moods and have a wide range of genres. The diversity of Tuvan musical instruments is amazing. The number of xöomei

Терада Мао — независимый автор, Япония. Эл. адрес: asao@aleatorik.jp

Terada Mao, Independent author, Japan.E-mail asao@aleatorik.jp 
сами также приезжают в Туву, в рамках программ по культурному обмену.

Тувинские музыканты находятся в постоянном творческом поиске. В самой музыке также наблюдается разностороннее развитие. Интересным автор называет и опыт исполнения хоомея женщинами. Хоомей исполняется вместе с забытыми старинными мелодиями, своеобразны еще не известные варианты хоомея. В случае использования хоомея в сочетании с современными формами музицирования существенно видоизменяется контекст функционирования самого хоомея. Тем не менее у многих современных тувинских хоомейжи исполнение этого уникального искусства становится более однообразным. С каждым годом увеличивается и число иностранных исполнителей хоомея.

Ключевые слова: Тува; тувинская музыка; Япония; японцы; горловое пение; хоомей; Хун-Хурту; Геннадий Тумат; музыкальный фестиваль; тувинские музыкальные инструменты; тувинские песни; Общество японо-тувинской дружбы performers in Japan is constantly rising. Japanese xöömei performers invite Tuvan xöömeiji every year to Japan and visit Tuva within the cultural exchange programs.

Tuvan musicians are in lasting creative pursuit. The music itself undergoes permanent versatile evolution. The author also takes interest in the best practices of women xöömei performers. Xöömei is being performed together with half-lost ancient melodies, the yet undiscovered variants of xöömei must be specific, as well. Performing xöömei in combination with modern forms of music-making significantly changes the context of xöommei's functionality. Nonetheless, many young xöömeiji started rendering this unique art in more and more monotonous way. Every year we also see an increase in the number of foreign xöömei-performers.

Keywords: Tuva; Tuvan music; Japan; Japanese; throat-singing; xöömei; Huun Huur Tu; Gennady Tumat; music festival; Tuvan musical instruments; Tuvan songs; Japan-Tuva Friendship Society

\section{Введение}

В современной Японии, как известно, наблюдается множество различных направлений музыкальной культуры, которые активно функционируют во всем своем многообразии (кроме традиционной японской музыки, классика, джаз, рок, поп, хип-хоп, рэп ...). С 1990-х годов началось знакомство японцев и с тувинской музыкой. Впервые тувинская музыка пришла в Японию в записях разных тувинских групп на компакт-дисках (CD). Первым тувинским исполнителем хоомея, посетившим в 1994 году Японию был Геннадий Тумат, ма́стерски продемонстрировавший перед японцами хоомей в живом исполнении. Тогда он приехал вместе с тувинской певицей Надеждой Куулар, с которой принимали участие в фестивале культуры, проходившем в г. Хакшу. С тех пор тувинская музыка начала вызывать огромный интерес у широкого круга японцев, особенно, у японской молодежи. Причем с каждым годом растет число не просто поклонников тувинской музыки, но и становится больше людей, реально осваивающих и серьезно использующих некоторые элементы тувинской музыки в своем творчестве.

В своей статье я поделюсь результатами своих наблюдений и соображениями о том, как воспринимается тувинская музыка в Японии, а также о том, как и в какую сторону развивается тувинская музыка на современ- 
ном этапе, основываясь на личных наблюдениях при многолетнем проживании в Туве с 2006 года.

\section{В поисках естественности}

Причин большого интереса японцев к тувинской музыке, на наш взгляд, несколько. Как известно, Япония - это урбанизированная страна, где почти не осталось сельской местности. Со всех сторон человека окружает индустриальный ландшафт. Житель города обделен и испытывает дефицит «живых» впечатлений. Человек оказался оторван от природы. Жизнь в мегаполисах не дает человеку «реальных, подлинных» природных ощущений и переживаний.

Природа Тувы впечатляет жителя огромного японского мегаполиса своей первозданностью и красотой. Такое же впечатление оказывает и тувинская музыка. Особенно хоомей поражает своей естественностью и «телесностью». На наш взгляд, именно это является наиболее интересным и ценным.

В древности в Японии тоже были инструменты и некоторые жанры устного народного творчества, по звучанию походившие на звуки хоомея (букв.: говорившие голосами, похожими на хоомей). Например, муккури - бамбуковый варган, бива - двух-, трех-, или иногда четырехструнный инструмент, на котором аккомпанировали себе исполнители сказаний и сказок, сэккёу - чтение ламой буддийской сутры гортанными звуками (голосом похожим на хоомей), саймон - сказительская традиция, когда рассказывающий сказку также использует гортанные звуки, нанивабуши - дуэт сказителей, когда один рассказывает сказку, а другой ему аккомпанирует на инструменте. Сейчас эти инструменты звучат все реже и реже, а некоторые исчезли из быта совсем, например, бива. В Японии почти не осталось и сказителей. Очень редким явлением стало чтение буддийскими ламами сутр голосом, похожим по звучанию на хоомей.

Возможно, ностальгия по этим милым сердцу, родным народным инструментам и по характерному, специфическому звучанию сказительского искусства заставляет японцев предпринять поиск аналогичных звучаний. Как нам представляется, наш личный «приход» к хоомею был обусловлен именно этим поиском. Наша грусть по тем старинным звукам компенсируется звуками хоомея. Этим можно, как нам кажется, объяснить и нашу влюбленность в хоомей. 
Кроме того, нам нравится и то, что тувинские песни могут выражать разнообразные настроения человека. Есть веселые и задорные песни жанра кожамык, а есть и лирические песни, которые выражают самые глубинные переживания человека. Например, такие песни, как «Өскүстүң ыры» (Песня сироты), «Чорумал бодум» (Песня путника), «Коңгурэй» и т. д.

Поражает воображение и многообразие тувинских музыкальных инструментов. Например, игил (двухструнный смычковый инструмент) имеет также много голосов, как и хоомей. В Японии нет такого инструмента. Хомус (варган) звучит как человеческий голос. Звучание бызаанчы (четырехструнного смычкового инструмента) тоже похоже на человеческий голос. Этот инструмент поет как человек, что нам особенно нравится. Есть в Туве и инструменты, похожие по внешнему виду на японские. Это - чанзы (двух-, или трехструнный щипковый инструмент) напоминает такие японские инструменты, как «шамисэн» и «саншин». Чадаган (многострунный щипково-ударный инструмент) близок к такому многострунному японскому инструменту, как кото. Мы перечислили всего лишь малую часть тувинских музыкальных инструментов. Все тувинские музыкальные инструменты имеют богатое и сложное звучание.

\section{Хоомей в Японии}

Количество исполнителей хоомея в Японии постоянно растет. Японские исполнители хоомея каждый год приглашают тувинских хоомейжи в Японию. И сами японские музыканты также приезжают в Туву, в рамках программ по культурному обмену. В 2001 и в 2004 гг. в Токио состоялись два конкурса исполнителей хоомея. В конкурсе приняли участие более 30 японских исполнителей. Время от времени японские исполнители проводят мастер-классы по хоомею, где в каждом классе собираются до 20 учеников.

Одним из самых активных поклонников тувинской музыки является Тодорики Масахико, периодически посещающий Туву в течение уже нескольких лет, когда ему позволяют его финансовые возможности. По специальности биолог, Тодорики стал почти специалистом и по тувинской музыке. Его опыт полевого сбора тувинской музыки беспрецедентен по количеству и качеству. Он не только собирает, но и сам активно изучает и исполняет тувинскую музыку. Из всех японских поклонников именно Тодорики Масахико является исполнителем тувинской музыки в ее классическом варианте, в отличие от других музыкантов, которые используют звучание хоомея в сочетании с другими направлениями современной 
музыки. Причем Т. Масахико занимается сбором и записью не только хоомея, но и тувинских народных песен всех жанров, многие из которых он сам исполняет на очень хорошем тувинском языке. Он является также создателем группы «Тарбаган» (в переводе с тувинского «Сурок»), в которой вместе с ним выступает Сага Харихико.

Одним из активных пропагандистов хоомея в Японии является Макигами Коуичи, лидер Общества японо-тувинской дружбы. Его учениками и последователями являются такие уже ставшие известными в Японии исполнители хоомея Ямакава Фуюки, Аояма Масааки, Обики Хироши, Окаяма Шууджи и другие (в том числе и автор данной статьи).

Окаяма Шууджи, родом из города Канадзава, впервые заинтересовался хоомеем, после того, как в 1998 г. услышал группу «Хун-Хурту». В 2000 г. в Туве занял 2-ое место в составе японской группы исполнителей. В 2001г. поехал в Индию и там научился играть на хомусе. В настоящее время исполняет хоомей и играет на хомусе в сопровождении электронных инструментов. С 2012 г. начал учиться исполнять роукёку - это тоже сказительская традиция, когда сказитель также использует гортанные звуки. Сейчас он имеет звание «мастер Роукёку». 2 апреля 2017 г. во время третьего конкурса, проведенного по инициативе Чодуры Тумат в г. Токио, среди японских исполнителей хоомея занял 1 место. Во время этого конкурса Окаяма Шууджи исполнил хоомей в сочетании с роукёку.

Обики Хироши - тоже один из поклонников хоомея. В 1999 г. основал группу «Вайодзу» (Vions), состоящую из четверых ребят и одной девушки. Также Обики Хироши дает уроки по хоомею. В Японии есть известная фирма анимэ «Нацумэ Юджинчё». Звуковое оформление одного из анимэ этой фирмы был сделан Обики Хироши, где он использовал игру на хомусе и исполнение хоомея. Кроме того, он принимает активное участие в детских передачах по телевидению, где также использует хоомей и хомус. Таким образом, можно сказать, что японцы стали слышать хоомей и в телепередачах.

Лауреат первого конкурса исполнителей хоомея Ямакава Фуюки открыл класс хоомея и проводит занятия уже в течение нескольких лет. В каждом классе обучение хоомею продолжается обычно в течение трех месяцев. В 2007 г., например, из 19 учеников, обучающихся в его классе, 17 человек составляли девушки. Кроме Фуюки Ямакавы в Токио мастер-классы по хоомею проводят еще четыре исполнителя.

Японских исполнителей хоомея в большинстве случаев отличает то, что хоомей привлекает их в первую очередь как источник новых, необычных, 
экзотических, иногда даже шокирующих звуков. Ямакава Фуюки, например, интересно применяет технику исполнения хоомея в сочетании с игрой на гитаре. Во всех этих случаях интерес к хоомею проявляется в основном с целью включения эффекта звучания хоомея в фактуру произведений современных видов музыкального искусства. В целом интерес исполнителей-музыкантов к хоомею преследует сугубо практическую цель и содействует наиболее полному раскрытию возможностей хоомея в его новых проявлениях. Например, в сочетании с японскими народными песнями и нанивабуши, или в переплетении с поп, рок, авангард жанрами или в сочетании с такими инструментами, как диджириду, каримба и т.д. Необходимо также отметить, что примерно такая же картина наблюдается и при практическом «освоении» хоомея музыкантами и из других стран, например, из Америки, Франции, Финляндии, Германии, Голландии и т. д.

\section{Мое открытие Тувы}

Впервые тувинскую музыку лично я услышала в 1999 г. на компакт диске в записи всемирно известной группы «Хун-Хурту». Эта музыка поразила меня своей причудливой природной «дикостью», красотой мелодий и интересным, необычным звучанием. Она привлекала внимание не только красотой своих мелодий, но и загадочностью звучания, т. е. в ней было какое-то таинство, и была какая-то загадка.

В 2003 г. я впервые приехала в Туву с группой японских исполнителей хоомея для участия в IV международном симпозиуме «Хоомей - феномен культуры народов Центральной Азии» и была ошеломлена тем, что в Туве было столько много исполнителей хоомея, особенно молодых. Кроме того, поразило также и то, что в Туве сохраняется столько много народных песен. Особый интерес вызывала также высокая по техничности и оригинальная исполнительская техника тувинских музыкантов, которые исполняют сыгыт, хоомей, каргыраа, эзенгилээр, борбаннадыр и многие другие разновидности этого искусства легко, играючи и даже весело. При всем при этом трудно рассказывать о тувинской музыке без ее связи с природой. Музыка тувинцев отражает и «рисует» их жизнь.

Второй раз в Туву я приезжала в 2004 г. для участия в фестивале «Сыгыт, хоомей на земле Овюрской», посвященном юбилею одного из известнейших исполнителей Тувы, Народного хоомейжи Республики Тыва Геннадия Тумата. После его визита в Японию, все японские поклонники 
тувинской музыки хорошо его знают, и до сих пор чтят его память. Поэтому на его юбилей приехала тогда из Японии довольно большая группа поклонников его таланта, прямых и заочных его учеников. Прямыми учениками считаются люди, которые успели получить хоть 1-2 урока на его мастер-классах, которые он дал за период своего непродолжительного пребывания в Японии. А заочные его ученики учились мастерству исполнения хоомея по его записям на аудиокассетах и на компакт-дисках и учились у его прямых учеников.

В третий раз я приехала в Туву в августе 2006 г. для того, чтобы пожить здесь и изучать традицию на месте.

Сейчас, прожив в Туве уже 11 лет, я наблюдаю, что музыкальная жизнь Тувы не стоит на месте, а постоянно развивается.

\section{Развитие хоомея в Туве}

Тувинские музыканты находятся в постоянном творческом поиске. В самой музыке также наблюдается разностороннее развитие (диверсификация) - это тоже вызывает большой интерес. Кроме исполнения классических образцов хоомея, молодые музыканты находят очень удачные варианты сочетания хоомея с такими направлениями современной музыки, как поп, рок, рэп, джаз, хип-хоп и т. д. В этом контексте особый интерес вызывало творчество безвременно ушедшего из жизни хоомейжи Аяса Данзырына.

Интересен, на мой взгляд, и опыт исполнения хоомея женщинами. Создан даже женский фольклорный ансамбль «Тыва кызы» (Дочери Тувы) под руководством Чодуры Тумат. Это тем более интересно, потому что в Туве традиционно исполнение хоомея являлось прерогативой мужчин. Много интересных исполнителей и в основном исполнительниц в Национальном оркестре. Кстати, среди японских поклонников тувинской музыки тоже очень много девушек, которые также активно посещают занятия мастер-классов по хоомею.

Особый интерес представляют забытые старинные мелодии, своеобразные, еще не известные варианты хоомея. В случае использования хоомея в сочетании с современными формами музицирования существенно видоизменяется контекст функционирования самого хоомея. Кроме того, нельзя забывать и о том, что хоомей в Туве - это не экспериментальный материал. То, что было создано их предками тувинские исполнители бе- 
режно развивают, и стараются сохранить традицию передачи этого искусства от поколения к поколению: от отца к сыну, от брата к брату и т. д. Например, Хунаштаар-оол Ооржак и его сыновья Байыр-оол и Виктор; братья Тумат Геннадия - Омак и Саян; исполнитель из Овюра Герман Куулар и его сыновья Мерген и Откун; Андрей Опей из Бай-Тайги и его сыновья Андриян и Сайын-Херел и дочь Аясмаа и т. д.

Тем не менее, по моим наблюдениям, у многих современных тувинских хоомейжи исполнение этого уникального искусства становится более однообразным. Из кожуунов республики стали мало приезжать такие яркие хоомейжи, какими были в свое время, например, Хунаштаар-оол Ооржак или Кара-Сал Ак-оол и многие другие. Хотелось бы слышать ярких, самобытных, ни на кого не похожих исполнителей среди молодежи. Актуальными становятся и вопросы преподавания хоомея с применением разнообразных методик обучения, максимально приближенных к традиционной системе обучения народных музыкантов.

В настоящее время с каждым годом увеличивается и число иностранных исполнителей хоомея. Кроме того, мы наблюдаем и фьюжн-проекты, когда тувинские музыканты играют совместно с музыкантами из разных стран. Значительный интерес сегодня представляют и те изменения, которые свидетельствуют о незаурядных творческих потенциях хоомея, о его способности ко все новым проявлениям. Многогранность хоомея позволяет говорить о неисчерпаемости его творческих возможностях. На наш взгляд, перспективным является также рассмотрение проблем «транскультурации» (межкультурного взаимодействия), при котором традиционная музыка Тувы «осваивается» музыкантами из разных стран и преобразуется в новые художественные формы, распространяющиеся по всему миру. Этот интересный аспект современного функционирования тувинской музыки рассматривался американским этномузыковедом, профессором Теодором Левиным в его книге «Где горы и реки поют: звук, музыка и номадизм в Туве и за ее пределами», написанной совместно с тувинским этномузыковедом В. Ю. Сузукей и изданной в 2006 г. в Америке, переизданной на русском языке в 2012 г. (Левин, Сузукей, 2012).

В дальнейшем, анализируя эти движущие силы современной культуры, можно обратиться и к таким темам, которые представляют особый интерес для специалистов в области культурной антропологии, этномузыковедения и социологии, изучающих и с эмпирической, и с теоретической точек зрения процессы глобализации культур в разных частях мира. 
А мое желание - это слышать такой же разнообразный хоомей, который был представлен в искусстве тувинских мастеров этого искусства в прошлом столетии. Это такие имена, как Сорукту Кыргыс, Кара-Сал Ак-оол, Максим Дакпай, Хунаштаар-оол Ооржак, Маржымал Ондар, Манчакай Сат, Алдын-оол Севек, Геннадий Тумат, Конгар-оол Ондар, Кайгал-оол Ховалыг, Анатолий Куулар и еще многие-многие другие. Я верю, что Тува богата еще не раскрытыми тайнами искусства хоомея.

\section{СПИСОК ЛИТЕРАТУРЫ}

Левин, Т., Сузукей, В. (2012) Музыка новых номадов. Горловое пение в Туве и за ее пределами / пер. с англ. И. Куна. М. : Классика-XXI. 332 с.

Дата поступления: 10.05.2017 2.

\section{REFERENCES}

Levin, T. and Suzukei, V. (2012) Muzyka novykh nomadov. Gorlovoe penie v Tuve i za ee predelami [Music of new nomads. Throat singing in Tuva and beyond] / transl. by Engl. by I. Kun. Moscow, Klassika-XXI. (In Russ.).

Submission date: 10.05 .2017$.

\section{Для циитирования}

Терада М. Развитие современной музыкальной культуры Тувы (взгляд из Японии) [Электронный ресурс] // Новые исследования Тувы. 2017, № 2. URL: https://nit. tuva.asia/nit/article/view/707 (дата обращения: ...). DOI: 10.25178/nit.2017.2.11

\section{For citation:}

Terada M. The development of contemporary music culture of Tuva (a view from Japan). The New Research of Tuva, 2017, no. 2 [on-line] Available at: https://nit.tuva.asia/nit/article/ view/707 (accessed: ...). DOI: 10.25178/nit.2017.2.11 